Article

\title{
The Relationship between Generalized and Abdominal Obesity with Diabetic Kidney Disease in Type 2 Diabetes: A Multiethnic Asian Study and Meta-Analysis
}

\author{
Ryan Eyn Kidd Man ${ }^{1,2}$, Alfred Tau Liang Gan ${ }^{1}$, Eva Katie Fenwick ${ }^{1,2} \odot$, Preeti Gupta ${ }^{1}$, \\ Mark Yu Zheng Wong ${ }^{1}$, Tien Yin Wong 1,2,3, Gavin Siew Wei Tan ${ }^{3}$, Boon Wee Teo ${ }^{4}$, \\ Charumathi Sabanayagam ${ }^{1,2}$ and Ecosse Luc Lamoureux $1,2, *$ (D) \\ 1 Singapore Eye Research Institute, Singapore National Eye Centre, Singapore 169856, Singapore; \\ man.eyn.kidd.ryan@seri.com.sg (R.E.K.M.); alfred.gan.t.1@seri.com.sg (A.T.L.G.); \\ eva.fenwick@seri.com.sg (E.K.F.); preeti.gupta@seri.com.sg (P.G.); mwyzknight@yahoo.com.sg (M.Y.Z.W.); \\ wong.tien.yin@singhealth.com.sg (T.Y.W.); charumathi.sabanayagam@seri.com.sg (C.S.) \\ 2 Duke-NUS Medical School, Singapore 169857, Singapore \\ 3 Singapore National Eye Centre, Singapore 168751, Singapore; gavin.tan@singhealth.com.sg \\ 4 Department of Nephrology, University Medicine Cluster, National University Health System, \\ Singapore 119074, Singapore; mdctbw@nus.edu.sg \\ * Correspondence: ecosse.lamoureux@seri.com.sg; Tel.: +65-6576 7382
}

Received: 26 September 2018; Accepted: 1 November 2018; Published: 5 November 2018

\begin{abstract}
This study examined the associations of body mass index (BMI), waist circumference (WC), waist-hip ratio (WHR) and waist-height ratio (WHtR) with diabetic kidney disease (DKD) in a clinical sample of Asian patients with type 2 diabetes (T2DM); substantiated with a meta-analysis of the above associations. We recruited 405 patients with T2DM (mean (standard deviation (SD)) age: 58 (7.5) years; $277(68.4 \%)$ male; $203(50.1 \%)$ with DKD) from a tertiary care centre in Singapore. DKD was defined as urinary albumin-creatinine ratio $>3.3 \mathrm{mg} / \mathrm{mmoL}$ and/or estimated glomerular filtration rate $<60 \mathrm{~mL} / \mathrm{min} / 1.73 \mathrm{~m}^{2}$. All exposures were analysed continuously and categorically (World Health Organization cut-points for BMI and WC; median for WHR and WHtR) with DKD using stepwise logistic regression models adjusted for traditional risk factors. Additionally, we synthesized the pooled odds ratio of 18 studies $(N=19,755)$ in a meta-analysis of the above relationships in T2DM. We found that overweight and obese persons (categorized using BMI) were more likely to have DKD compared to under/normal weight individuals, while no associations were found for abdominal obesity exposures. In meta-analyses however, all obesity parameters were associated with increased odds of DKD. The discordance in our abdominal obesity findings compared to the pooled analyses warrants further validation via longitudinal cohorts.
\end{abstract}

Keywords: obesity; body mass index; waist-hip ratio; waist circumference; waist-height ratio; meta-analysis; diabetic kidney disease

\section{Introduction}

Diabetic kidney disease (DKD), a serious microvascular complication of diabetes, is defined as decreased renal function (glomerular filtration rate (GFR)) with persistent clinically detectable proteinuria (albuminuria) [1]; and occurs in approximately $25-40 \%$ of patients with diabetes [2]. Given the dual problems of a significant risk of progression from DKD to end-stage renal disease (ESRD) [3], increased concomitant cardiovascular disease [4], and mortality [5], it is important to identify patients 
at risk of DKD, understand the underlying pathogenic pathways, and initiate renal and cardiovascular therapies based on the knowledge of these causal mechanisms.

Obesity is rapidly reaching epidemic proportions globally and Asia is no exception, particularly with the adoption of an increasingly westernized diet and sedentary lifestyle [6]. Obesity is an established risk factor for diabetes and hypertension $[7,8]$, both linked with the development of DKD [9]. According to the World Health Organization (WHO) [10], there are two separate classifications of obesity namely 'generalized', defined as body mass index (BMI, calculated as weight in kilograms $(\mathrm{kg})$ divided by height in meters $(\mathrm{m})$ squared) of $\geq 30 \mathrm{~kg} / \mathrm{m}^{2}$; and 'central/abdominal', assessed using waist circumference (WC) and / or waist-to-hip/height ratio (WHR/WHtR). While there is emerging evidence suggesting that both forms [11-17] contribute to the risk of DKD, independent of diabetes and/or hypertension, it is still unclear which one contributes more to the risk of DKD due to their close inter-relationship [18-20].

Our group has previously shown a differential association of BMI and WHR with diabetic retinopathy (DR), a visual microvascular complication of diabetes [21]. This lack of clarity is particularly problematic in patients with type 2 diabetes (T2DM) as up to half with impaired GFR have no overt albuminuria (non-albuminuric DKD) [22,23], which adds an additional level of uncertainty to the role of these two measures of obesity in the pathogenesis of DKD. In fact, recent research has advocated that GFR may be a better indicator of DKD, as urinary albumin-creatinine ratio (UACR) levels do not necessarily reflect actual levels of renal function [1].

In this study, we therefore examined the associations between generalized obesity (defined as BMI) and abdominal obesity (assessed using three different measures: WC, WHR and WHtR) with DKD (assessed using UACR and estimated GFR (eGFR)) in a well-characterized sample of Asian patients with T2DM. We also conducted a meta-analysis of studies evaluating the relationship of these two obesity indices with DKD in patients with T2DM to situate our findings in the broader context.

\section{Materials and Methods}

\subsection{Study Population}

Participants were recruited as part of the Singapore Diabetes Management Project (S-DMP), a clinic-based, cross-sectional study investigating the clinical, behavioural, and environmental barriers associated with optimal diabetes care in patients with diabetes [21]. In brief, we recruited 498 individuals aged $\geq 21$ years, with Types 1 and 2 diabetes, from the Singapore National Eye Centre between 2010 to 2013. All participants had sufficient hearing enabling normal conversations, were not cognitively impaired (assessed using the 6 item Cognitive Impairment Test) [24], and lived independently in the community. Diabetes was physician-diagnosed, with the information retrieved from participants' case notes. Written informed consent was obtained from all participants and the study was approved by the Singapore Centralized Institutional Review Board (Reference: 2010/470/A) and adhered to the tenets of the Declaration of Helsinki. For the current study, participants of Asian ethnicity (Chinese, Malays and Indians) with T2DM who had available eGFR data, as well as gradable retinal photographs and optical coherence tomography (OCT; Cirrus Version 3.0; Carl Zeiss Meditec, Jena, Germany) images of $\geq 6$ signal strength to enable grading of diabetic retinopathy (DR) presence, a covariate in our multivariable adjusted model; $(N=405$; comprising 303 Chinese, 35 Malays and 67 Indians) were included.

\subsection{Assessment of Obesity Exposures}

Participants were required to remove shoes and heavy objects such as belts, phones, keys, and wallets. Height was measured in centimeters $(\mathrm{cm})$ using a wall-mounted measuring tape and weight in $\mathrm{kg}$ using a digital scale. BMI was calculated as weight in $\mathrm{kg}$ divided by the square of height in meters $\left(\mathrm{kg} / \mathrm{m}^{2}\right)$, and categorized into underweight $\left(<18.5 \mathrm{~kg} / \mathrm{m}^{2}\right)$, normal $\left(18.5-24.9 \mathrm{~kg} / \mathrm{m}^{2}\right)$, overweight $\left(25-29.9 \mathrm{~kg} / \mathrm{m}^{2}\right)$, and obese $\left(\geq 30 \mathrm{~kg} / \mathrm{m}^{2}\right)$ according to WHO-defined international BMI 
cut points [10], in order to maintain parity with previous studies in meta-analysis. However, due to the small sample size of individuals who were underweight $(N=3)$ and obese $(N=77)$, the underweight and normal weight categories, as well as those who were overweight and obese, were combined for analytical purposes.

Both waist and hip circumference values were assessed using a non-stretchable medical tape. Hip measurements $(\mathrm{cm})$ were made at the maximal protuberance of the buttocks, while waist circumference $(\mathrm{cm})$ was taken at the smallest horizontal girth between the costal margins and the iliac crests at the end of tidal expiration. Abdominal obesity was defined as WC >94 cm for males and $80 \mathrm{~cm}$ for females [25]; WHR as WC divided by the hip circumferences [21]; and WHtR as WC divided by height (in $\mathrm{cm}$ ) [26]. Established WHR [25] and WHtR [27] categorizations were not utilized in the main analyses due to a need for a common unit of classification with previous WHR/WHtR and DKD studies when synthesizing data for the meta-analysis. We reran the analyses with established thresholds for the two exposures and the results are shown in Table S1.

\subsection{Assessment of $D K D$}

Serum creatinine was assessed using the Roche Integra 800 colorimetric assay (Roche Diagnostics Ltd., Rotkreuz, ZG, Switzerland), calibrated to the standards set by the National Institute of Standards and Technology (NIST). Estimated GFR (eGFR; in $\mathrm{mL} / \mathrm{min} / 1.73 \mathrm{~m}^{2}$ ) was calculated from serum creatinine using the Chronic Kidney Disease Epidemiology Collaboration (CKD-EPI) equation [28]. A mid-stream urine sample was also collected using $50 \mathrm{~mL}$ specimen containers and assessed using the Roche Integra 800 colorimetric assay (Roche Diagnostics Ltd., Rotkreuz, ZG, Switzerland) to determine urinary albumin-creatinine ratio (UACR in $\mathrm{mg} / \mathrm{mmol}$ ). DKD was defined as eGFR $<60 \mathrm{~mL} / \mathrm{min} / 1.73 \mathrm{~m}{ }^{2}$ $(N=81)$ [29], and/or UACR $>3.39 \mathrm{mg} / \mathrm{mmol}$ (equivalent to $30 \mathrm{mg} / \mathrm{g})(N=122)$ in this study. The CKD-EPI formula has been validated extensively in Asian populations with accuracy of estimating CKD similar to that reported in Caucasian studies [30,31].

\subsection{Assessment of Covariates}

A standardized questionnaire was used to collect information on patients' demographic and socioeconomic characteristics (e.g., age, gender, income, education), lifestyle factors (e.g., smoking), and medical history (e.g., duration of diabetes, presence of cardiovascular disease (CVD, defined as self-reported history of angina, stroke and myocardial infarction)). A digital BP machine (Dinamap Pro 100 V2, GE Heathcare, Buckinghamshire, UK) was used to perform blood pressure (BP) measurements. Non-fasting venous blood samples $(50 \mathrm{~mL})$ were collected by a trained nurse to assess $\mathrm{HbA} 1 \mathrm{C}$, serum total cholesterol, high-density lipoprotein cholesterol (HDL), low-density lipoprotein cholesterol (LDL), and triglycerides. Serum total cholesterol, HDL, LDL and triglycerides were assessed via spectrophotometry conducted using the Beckman Coulter Unicel DxC 800 (Beckman Coulter Inc., Brea, CA, USA), while $\mathrm{HbA1C}$ was quantified using immunoassay conducted with the Roche CobasC501 (Roche Diagnostics) [32]. 11 samples were analysed at the Singapore General Hospital Hematology Laboratory. Presence of diabetic retinopathy (DR) and diabetic macular edema (DME) in the worst eye was graded from 2-field fundus photographs (Canon CR6-45 NM; Canon Inc., Tokyo, Japan) using the modified Airlie House classification system and confirmed with central macular thickness scans of $\geq 6$ signal strength taken using spectral-domain optical coherence tomography (SD-OCT-Cirrus Version 3.0; Carl Zeiss Meditec, Jena, Germany). Hypertension was defined as having a systolic BP (SBP) of $\geq 140 \mathrm{~mm} \mathrm{Hg}$ or a diastolic BP (DBP) of $\geq 90 \mathrm{mmHg}$ or self-reported history of hypertension or anti-hypertensive medication use.

\subsection{Statistical Analysis}

All statistical analyses were performed using Intercooled Stata version 14.2 for Windows (StataCorp., Lake Station, TX, USA). Patients' characteristics with and without DKD were compared using the Chi-square statistic for proportions, and a $t$ test and/or Mann-Whitney $U$ test for means 
as appropriate to the observed distribution of continuous variables. Normality was checked, and variables were transformed as appropriate. Multivariable binary logistic regression models were used to assess the associations of BMI, WC, WHR and WHtR with the presence of DKD. The exposures were analysed continuously (per SD increase) and categorically (based on the WHO cut-points for BMI and WC; and in quantiles based on the median values for WHR and WHtR). Two models were developed for each exposure, initially including age and gender (Model 1) and additionally for known risk factors of DKD (ethnicity, smoking, presence of CVD, diabetes duration, HbA1C, SBP, BMI, total cholesterol to HDL ratio, presence of DR, use of anti-hypertensive medication, and insulin use) (Model 2) using backward-stepwise variable selection, with threshold significance level for variable removal specified at 0.05 . Supplementary subgroup analyses were also conducted for DKD categorized using UACR and eGFR alone to assess the impact of obesity measures on non-albuminuric DKD. Analyses for DKD severity were not undertaken in overall and subgroup analyses; the former because there are no established severity levels for DKD presence defined using both UACR and eGFR values, and the latter due to the small number of patients with more severe disease $(N=2$ for macroalbuminuria [UACR > $33.9 \mathrm{mg} / \mathrm{mmol}$ (equivalent to $300 \mathrm{mg} / \mathrm{g}$ )); $N=14$ for eGFR between $15-29 \mathrm{~mL} / \mathrm{min} / 1.73 \mathrm{~m}{ }^{2}$; and $N=8$ for eGFR $<15 \mathrm{~mL} / \mathrm{min} / 1.73 \mathrm{~m}^{2}$ ).

As previous work $[17,21]$ have demonstrated gender-specific differences in the associations of the different measures of obesity with cardio-metabolic outcomes (e.g., DR and DKD), gender-stratified analyses were conducted. We further considered stratified analyses to isolate the relationships between generalized and abdominal obesity only with DKD. However, the above was not possible due to the small numbers of these individuals $(N=35$ and $N=38$ for individuals with generalized and abdominal obesity only, respectively). We instead adjusted for these parameters in the respective analyses (i.e., adjusting for WC in the BMI-DKD relationship and adjusting for BMI in the abdominal obesity-DKD associations) to account for the mutually confounding effects (Table S1). A $p$ value of $<0.05$ was deemed statistically significant.

\subsection{Meta-Analysis}

The meta-analysis was conducted in accordance with the MOOSE guidelines. To summarize results from the present and previous cross-sectional studies evaluating the relationship between BMI and WHR/WHtR with DKD in persons with T2DM, relevant English-language peer-reviewed clinicand population-based studies were systematically identified using an electronic literature search of Medline until 31 May 2018, with a combination of keywords (Figure 1) and by scanning relevant reference lists. Previous research assessing the association of generalized obesity and/or abdominal obesity using objectively assessed BMI; and WC or WHR/WHtR, respectively, with DKD (categorized using UACR and/or eGFR) were included. In addition, studies evaluating the categorical BMI- and waist circumference/hip/height ratio-DKD relationships had to specify a cut-off for obesity, instead of simply categorizing and comparing the effects from different quantiles of measurement, due to the need for a common measurement unit when estimating the pooled effect of the exposure on the outcome. This search strategy identified 17 studies (Figure 1). 


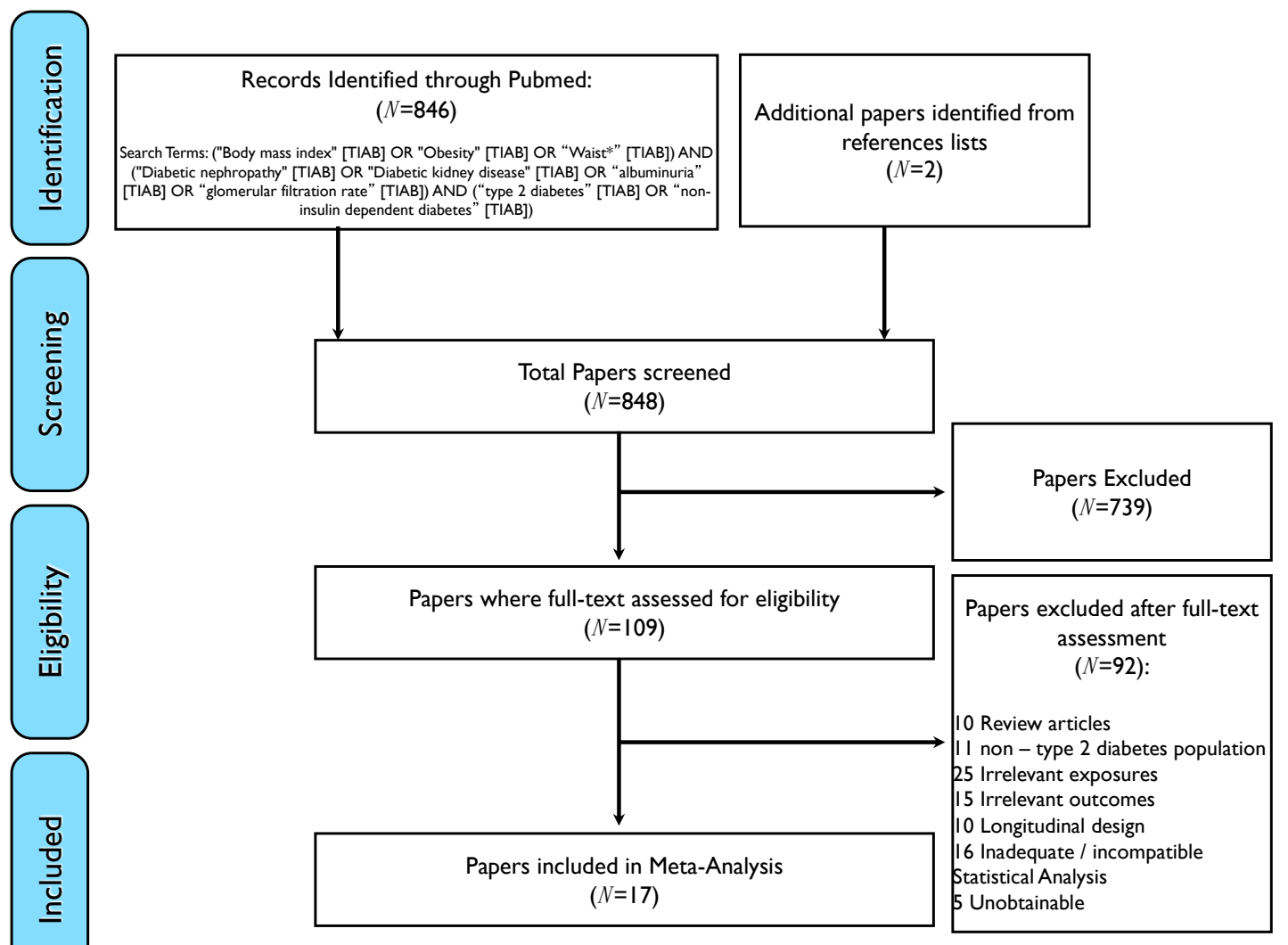

Figure 1. Flowchart showing search terms and article selection for meta-analysis.

Random effects meta-analysis was performed to synthesize study effects and heterogeneity was quantified using the I-squared statistic, as substantial variability across studies, due to non-standardized cut-offs for variable categorization being used, was expected. A higher I-squared value meant greater heterogeneity in study effects. All results were expressed in odds ratios (OR) per unit increase for continuous variables, and categorically as obese versus non-obese (for BMI and waist circumference exposures) and per category increase (for waist hip/height ratio exposures). With multiple ORs for waist-hip/height ratio reported in the studies by Wang et al. [33] and Hu et al. [16]. selected effects from each study were averaged prior to incorporating the pooled effects in the meta-analysis. Specifically, in the study by Wang and associates, the per-quartile effects corresponding to definitions of DKD based on albuminuria and eGFR were averaged. In the study by $\mathrm{Hu}$ and colleagues, a per-category effect by averaging the effects comparing tertile 2 vs. 1 and tertile 3 vs. 2 was obtained. To obtain standard error estimates of the averaged effects which account for statistical dependency between reported effects [34], model-based estimates of correlation between the reported effects in each study using a logistic regression analysis of outcome frequency counts that were reported was recorded. Sensitivity of the meta-analysis results to varying correlation was checked. Other methods that may incorporate multiple correlated effects directly in the meta-analysis were considered, but the number of waist-hip ratio studies was too small to make valid inferences when employing such methods [35,36].

\section{Results}

The mean age (SD) of the 405 patients included in analyses was 58 (7.5) years and $277(68.4 \%)$ were male. The mean (SD) BMI was $26.5(4.2) \mathrm{kg} / \mathrm{m}^{2}, 93.3(10.6) \mathrm{cm}$ for WC, $0.6(0.1)$ for WHtR, and 0.9 (0.1) for WHR. Those with DKD comprised 203 (50.1\%) of the sample and were likely to be older, male, have a higher total to HDL cholesterol ratio, higher UACR, longer duration of diabetes, higher $\mathrm{SBP}$, greater WHR, and were more likely to be on insulin and have DR (all $p<0.05$; Table 1 ). 
Table 1. Comparison of participant characteristics stratified by presence of diabetic kidney disease (DKD) *.

\begin{tabular}{|c|c|c|c|c|}
\hline \multirow[b]{2}{*}{ Variable } & \multicolumn{4}{|c|}{ Mean (SD) or Number (\%) } \\
\hline & $\begin{array}{l}\text { Overall }(N \\
\quad=405)\end{array}$ & $\begin{array}{l}\text { No DKD } \\
(N=202)\end{array}$ & $\begin{array}{l}\text { DKD }^{*} \\
(N=203)\end{array}$ & $p^{\wedge}$ \\
\hline Age (years) & $58.0(7.5)$ & $57.0(7.4)$ & $58.9(7.5)$ & 0.012 \\
\hline \multicolumn{5}{|l|}{ Gender } \\
\hline Male & $277(68.4)$ & $130(64.4)$ & $147(72.4)$ & \multirow[t]{2}{*}{0.081} \\
\hline Female & $128(31.6)$ & $72(35.6)$ & $56(27.6)$ & \\
\hline \multicolumn{5}{|l|}{ Race } \\
\hline Chinese & $303(74.8)$ & $149(73.8)$ & $154(75.9)$ & \multirow[t]{3}{*}{0.193} \\
\hline Malay & $35(8.6)$ & $14(6.9)$ & $21(10.3)$ & \\
\hline Indian & $67(16.5)$ & 39 (19.3) & $28(13.8)$ & \\
\hline Total to HDL cholesterol ratio & $4.2(1.3)$ & $4.0(1.1)$ & $4.4(1.4)$ & 0.004 \\
\hline $\mathrm{ACR}(\mathrm{mg} / \mathrm{mmoL})$ & $22.2(62.8)$ & $1.3(0.8)$ & $43.0(83.8)$ & $<0.001$ \\
\hline $\mathrm{HbA1C}(\%)$ & $7.8(1.6)$ & $7.5(1.4)$ & $8.1(1.6)$ & $<0.001$ \\
\hline Systolic blood pressure (mmHg) & $136.3(17.8)$ & $132.2(16.4)$ & $140.5(18.2)$ & $<0.001$ \\
\hline Diastolic blood pressure (mmHg) & $77.3(9.8)$ & $76.4(9.1)$ & $78.2(10.5)$ & 0.058 \\
\hline Diabetes duration (years) & $13.3(9.3)$ & $11.1(8.5)$ & $15.6(9.5)$ & $<0.001$ \\
\hline \multicolumn{5}{|l|}{ Insulin use } \\
\hline No insulin use & $347(85.7)$ & $183(90.6)$ & $164(80.8)$ & \multirow[t]{2}{*}{0.005} \\
\hline Insulin use & $58(14.3)$ & $19(9.4)$ & $39(19.2)$ & \\
\hline \multicolumn{5}{|l|}{ Presence of DR } \\
\hline No & $178(44.0)$ & $106(52.5)$ & $72(35.5)$ & \multirow[t]{2}{*}{0.001} \\
\hline Yes & $227(56.0)$ & $96(47.5)$ & $131(64.5)$ & \\
\hline \multicolumn{5}{|l|}{ Anti-hypertensive medication use } \\
\hline No & $259(64.0)$ & $137(67.8)$ & $122(60.1)$ & \multirow[t]{2}{*}{0.106} \\
\hline Yes & $146(36.0)$ & $65(32.2)$ & $81(39.9)$ & \\
\hline \multicolumn{5}{|l|}{ Generalized Obesity categories } \\
\hline Normal or underweight $\left(\mathrm{BMI}<25 \mathrm{~kg} / \mathrm{m}^{2}\right)$ & $168(41.5)$ & $94(46.5)$ & $74(36.5)$ & \multirow[t]{3}{*}{0.104} \\
\hline Overweight (BMI 25-29.9 kg/m²) & $160(39.5)$ & $71(35.1)$ & $89(43.8)$ & \\
\hline Obese $\left(\mathrm{BMI} \geq 30 \mathrm{~kg} / \mathrm{m}^{2}\right)$ & $77(19.0)$ & $37(18.3)$ & $40(19.7)$ & \\
\hline $\operatorname{BMI}\left(\mathrm{kg} / \mathrm{m}^{2}\right)$ & $26.5(4.2)$ & $26.3(4.3)$ & $26.7(4.1)$ & 0.331 \\
\hline \multicolumn{5}{|l|}{ Abdominal Obesity categories } \\
\hline Normal or underweight & $127(31.4)$ & $66(32.7)$ & $61(30.0)$ & \multirow[t]{2}{*}{0.569} \\
\hline $\begin{array}{l}\text { Overweight or obese (waist circumference }>90 \mathrm{~cm} \\
\text { for males; }>80 \mathrm{~cm} \text { for females }\end{array}$ & $278(68.6)$ & $136(67.3)$ & $142(70.0)$ & \\
\hline Waist circumference $(\mathrm{cm})$ & $93.3(10.6)$ & $92.7(10.7)$ & $94.0(10.4)$ & 0.206 \\
\hline \multicolumn{5}{|l|}{ Waist-hip ratio quantiles } \\
\hline Lower quantile (0.72-0.94) & $203(50.1)$ & $112(55.4)$ & $91(44.8)$ & \multirow[t]{2}{*}{0.033} \\
\hline Upper quantile (0.95-1.13) & $202(49.9)$ & $90(44.6)$ & $112(55.2)$ & \\
\hline Waist-hip ratio & $0.9(0.1)$ & $0.9(0.1)$ & $1.0(0.1)$ & 0.017 \\
\hline \multicolumn{5}{|l|}{ Waist-height ratio quantiles } \\
\hline Lower quantile (0.41-0.56) & $203(50.1)$ & $109(54.0)$ & $94(46.3)$ & \multirow[t]{2}{*}{0.123} \\
\hline Upper quantile (0.57-0.80) & $202(49.9)$ & $93(46.0)$ & $109(53.7)$ & \\
\hline Waist-height ratio & $0.6(0.1)$ & $0.6(0.1)$ & $0.6(0.1)$ & 0.168 \\
\hline
\end{tabular}

${ }^{\wedge} t$-test or chi-squared test. ${ }^{*}$ Based on eGFR $\left(<60 \mathrm{~mL} / \mathrm{min} / 1.73 \mathrm{~m}^{2}\right)$ and urinary albumin creatinine ratio ( $>3.3 \mathrm{mg} / \mathrm{mmol}$ ). ACR: albumin-creatinine ratio, HbA1C: haemoglobin A1C, HDL: high density lipoprotein, DR: diabetic retinopathy, BMI: body mass index

In models adjusted for age and gender (Table 2, Model 1), no associations were found between BMI analyzed continuously and presence of DKD. However, those categorized as overweight/obese were more likely to have DKD (OR: 1.69, 95\% CI: 1.12, 2.55), compared to normal/underweight individuals and this association persisted after multivariable adjustment (Table 2, Model 2). No associations were, however, found between any of the remaining abdominal obesity parameters (WC, WHR and WHtR) with DKD. As being underweight has been found to be associated with DKD in some studies $[37,38]$ we conducted additional Supplementary analyses excluding underweight individuals but found 
no change in the direction, nor significance of the above reported associations (data not shown). In addition, as iterated previously, we reran the analyses for WHR and WHtR using established abdominal obesity thresholds and did not find any change in the direction, nor significance, of the associations (Table S1). Mutually adjusting for generalized and abdominal obesity exposures showed results similar to that presented in our main tables (Table S1).

Table 2. Multivariable adjusted association of body mass index, waist circumference, waist-hip-ratio and waist-height-ratio with diabetic kidney disease ${ }^{*}(N=405)$.

\begin{tabular}{|c|c|c|c|c|c|}
\hline & & \multicolumn{4}{|c|}{ Odds Ratio (95\% CI) } \\
\hline & & Model 1 & $p$ & Model 2 & $p$ \\
\hline \multirow[t]{2}{*}{ Body mass index } & Overweight or obese & 1.69 (1.12 to 2.55$)$ & 0.012 & 1.59 (1.04 to 2.41$)$ & 0.030 \\
\hline & Per SD increase & 1.20 (0.97 to 1.47$)$ & 0.091 & 1.14 (0.93 to 1.42$)$ & 0.213 \\
\hline \multirow[t]{2}{*}{ Waist circumference } & Overweight or obese & $1.62(0.94$ to 2.78$)$ & 0.084 & $1.25(0.70$ to 2.24$)$ & 0.457 \\
\hline & Per SD increase & 1.13 (0.93 to 1.38$)$ & 0.228 & 1.08 (0.88 to 1.32$)$ & 0.484 \\
\hline \multirow[t]{2}{*}{ Waist-hip-ratio } & $\begin{array}{c}\text { Upper quantile } \\
(0.95-1.13)\end{array}$ & $1.39(0.92$ to 2.10$)$ & 0.114 & 1.27 (0.83 to 1.93$)$ & 0.271 \\
\hline & Per SD increase & $1.23(0.97$ to 1.55$)$ & 0.086 & 1.14 (0.90 to 1.45$)$ & 0.281 \\
\hline \multirow[t]{2}{*}{ Waist-height-ratio } & $\begin{array}{c}\text { Upper quantile } \\
(0.57-0.80)\end{array}$ & 1.41 (0.95 to 2.10$)$ & 0.091 & $1.28(0.85$ to 1.92$)$ & 0.239 \\
\hline & Per SD increase & $1.18(0.97$ to 1.45$)$ & 0.099 & 1.11 (0.91 to 1.37$)$ & 0.304 \\
\hline
\end{tabular}

Model 1: Age and gender. Model 2: Model $1+$ ethnicity, smoking, presence of cardiovascular disease, diabetes duration, HbA1c, systolic blood pressure, total cholesterol to high density cholesterol ratio, presence of retinopathy, use of anti-hypertensive medication, and insulin use using stepwise regression. * Based on eGFR $(<60 \mathrm{~mL} / \mathrm{min}$ / $\left.1.73 \mathrm{~m}^{2}\right)$ and/or urinary albumin creatinine ratio (>3.39 mg/mmol). SD: standard deviation.

In models stratified by gender, we found no association of any of the generalized obesity parameters with DKD (Table 3).

Table 3. Multivariable * adjusted and gender-stratified associations of body mass index, waist circumference, waist-hip-ratio and waist-height-ratio with diabetic kidney disease $(N=405)$.

\begin{tabular}{|c|c|c|c|c|c|}
\hline & & \multicolumn{2}{|l|}{ Male } & \multicolumn{2}{|l|}{ Female } \\
\hline & & $\begin{array}{l}\text { Odds Ratio } \\
\text { (95\% CI) }\end{array}$ & $p$ & $\begin{array}{l}\text { Odds Ratio } \\
\text { (95\% CI) }\end{array}$ & $p$ \\
\hline \multirow[t]{2}{*}{ Body mass index } & Overweight or obese & 1.45 (0.88 to 2.39$)$ & 0.149 & 1.88 (0.86 to 4.13$)$ & 0.115 \\
\hline & Per SD increase & $1.08(0.82$ to 1.42$)$ & 0.581 & $1.23(0.87$ to 1.73$)$ & 0.240 \\
\hline \multirow[t]{2}{*}{ Waist circumference } & Overweight or obese & 1.45 (0.88 to 2.37$)$ & 0.141 & $1.69(0.56$ to 5.11$)$ & 0.356 \\
\hline & Per SD increase & 0.71 (0.42 to 1.18$)$ & 0.188 & 1.35 (0.91 to 1.98$)$ & 0.133 \\
\hline \multirow[t]{2}{*}{ Waist-hip-ratio } & $\begin{array}{c}\text { Upper quantile } \\
(0.95-1.13)\end{array}$ & 1.12 (0.68 to 1.85$)$ & 0.662 & 1.71 (0.78 to 3.73$)$ & 0.181 \\
\hline & Per SD increase & $0.99(0.70$ to 1.39$)$ & 0.932 & 1.41 (0.93 to 2.14$)$ & 0.106 \\
\hline \multirow[t]{2}{*}{ Waist-height-ratio } & $\begin{array}{l}\text { Upper quantile } \\
(0.57-0.80)\end{array}$ & 1.13 (0.69 to 1.85$)$ & 0.632 & $1.68(0.81$ to 3.50$)$ & 0.164 \\
\hline & Per SD increase & 1.08 (0.62 to 1.85$)$ & 0.794 & $1.18(0.83$ to 1.69$)$ & 0.360 \\
\hline
\end{tabular}

* Adjusted for age, gender, ethnicity, smoking, presence of cardiovascular disease, diabetes duration, HbA1c, systolic blood pressure, total cholesterol to high density cholesterol ratio, presence of retinopathy, use of anti-hypertensive medication, and insulin use using stepwise regression. * Based on eGFR $\left(<60 \mathrm{~mL} / \mathrm{min} / 1.73 \mathrm{~m}^{2}\right)$ and /or urinary albumin creatinine ratio $(>3.39 \mathrm{mg} / \mathrm{mmoL})$. SD: standard deviation

The meta-analysis synthesized data from 18 studies (including the present one) for a total of 19,755 participants (Table S2) [11-17,33,39,40]. For the effects of continuous BMI and obesity (dichotomized BMI) on DKD, we included data from five [11,13,17,40] and four [12,14,39] studies in the meta-analysis, respectively. We found that every $5 \mathrm{~kg} / \mathrm{m}^{2}$ increase in BMI was on average associated with a $43 \%$ increase in the odds of DKD (OR: 1.40, 95\% CI: 1.27, 1.61, I-squared: $0 \%$ ), while 
obesity was associated with a $65 \%$ increase in the odds of renal disease (OR: 1.65, 95\% CI: 1.15, 2.34, I-squared: 77.2\%; Figure 2).

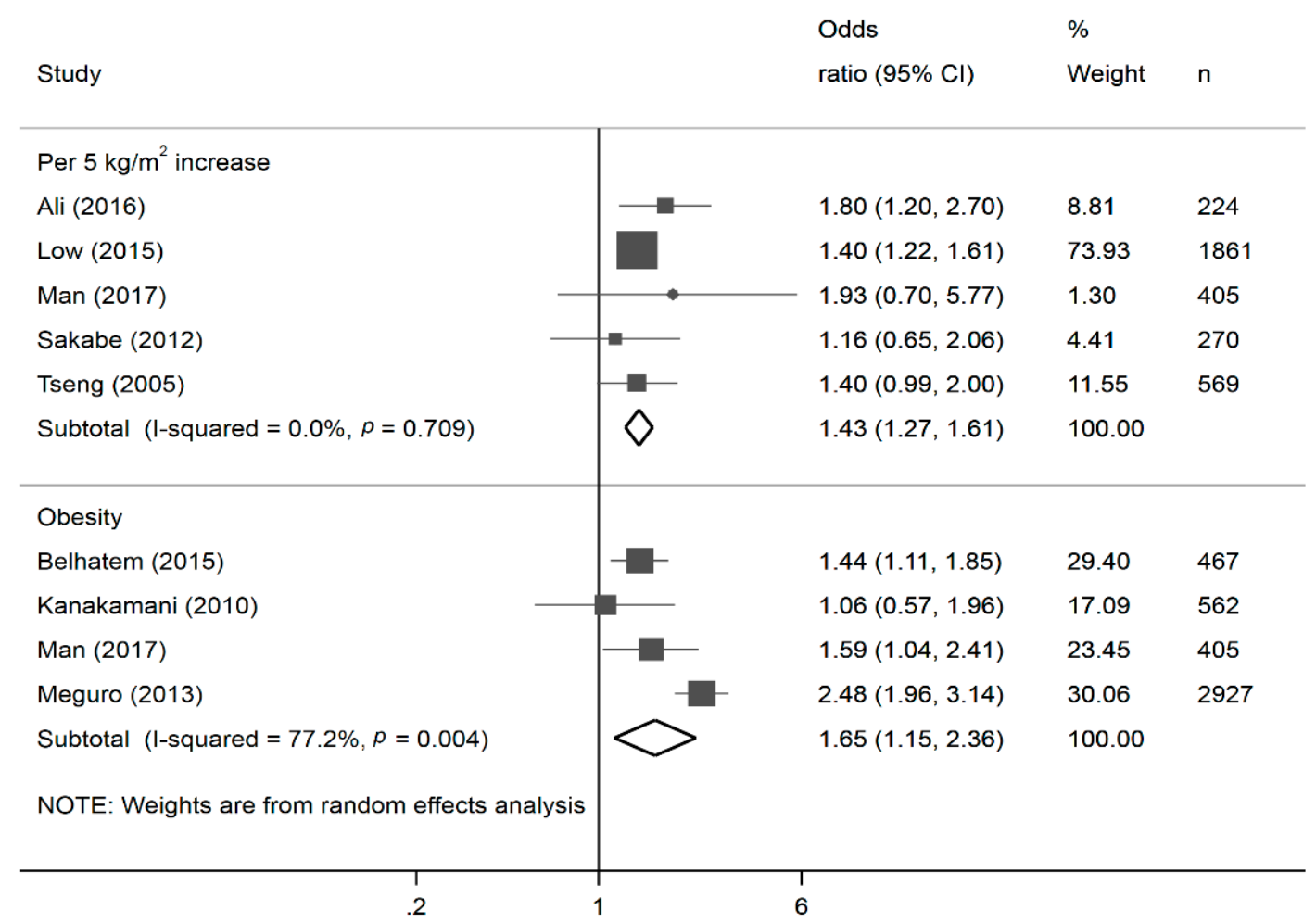

Figure 2. Forest plots * of the association of continuous and categorical body mass index (BMI) with diabetic kidney disease. * The size of the box of each study effect corresponds to the relative weight given to that study in the meta-analysis; the diamond refers to the overall pooled estimates with $95 \%$ confidence interval.

A total of 4 and 6 studies were included in the meta-analysis of the effects of continuous waist circumference [39,41,42] and abdominal obesity [43-47] (dichotomized waist circumference), respectively. A $1 \mathrm{~cm}$ increase in waist circumference was on average associated with a $2 \%$ increase in the odds of renal disease (OR: 1.02, 95\% CI: 1.01, 1.03, I-squared: 19.4\%), while abdominal obesity was associated with an $80 \%$ increase in the odds of renal disease (OR: 1.80, 95\% CI: 1.39, 2.34, I-squared: $59.1 \%$; Figure 3).

Data from six studies (three each) were included in the meta-analysis of the effects of continuous $[15,17]$ and categorized $[16,33]$ WHR/WHtR. While we found a significant association between increased waist-hip ratio and likelihood of DKD continuously (OR per 0.1-unit increase: 1.47, 95\% CI 1.25, 1.74, I-squared: $28.2 \%$ ), this association became attenuated when analyzed categorically (OR per category increase: 1.10, 95\% CI 0.99, 1.23, I-squared: 52.8\%; Figure 4). 


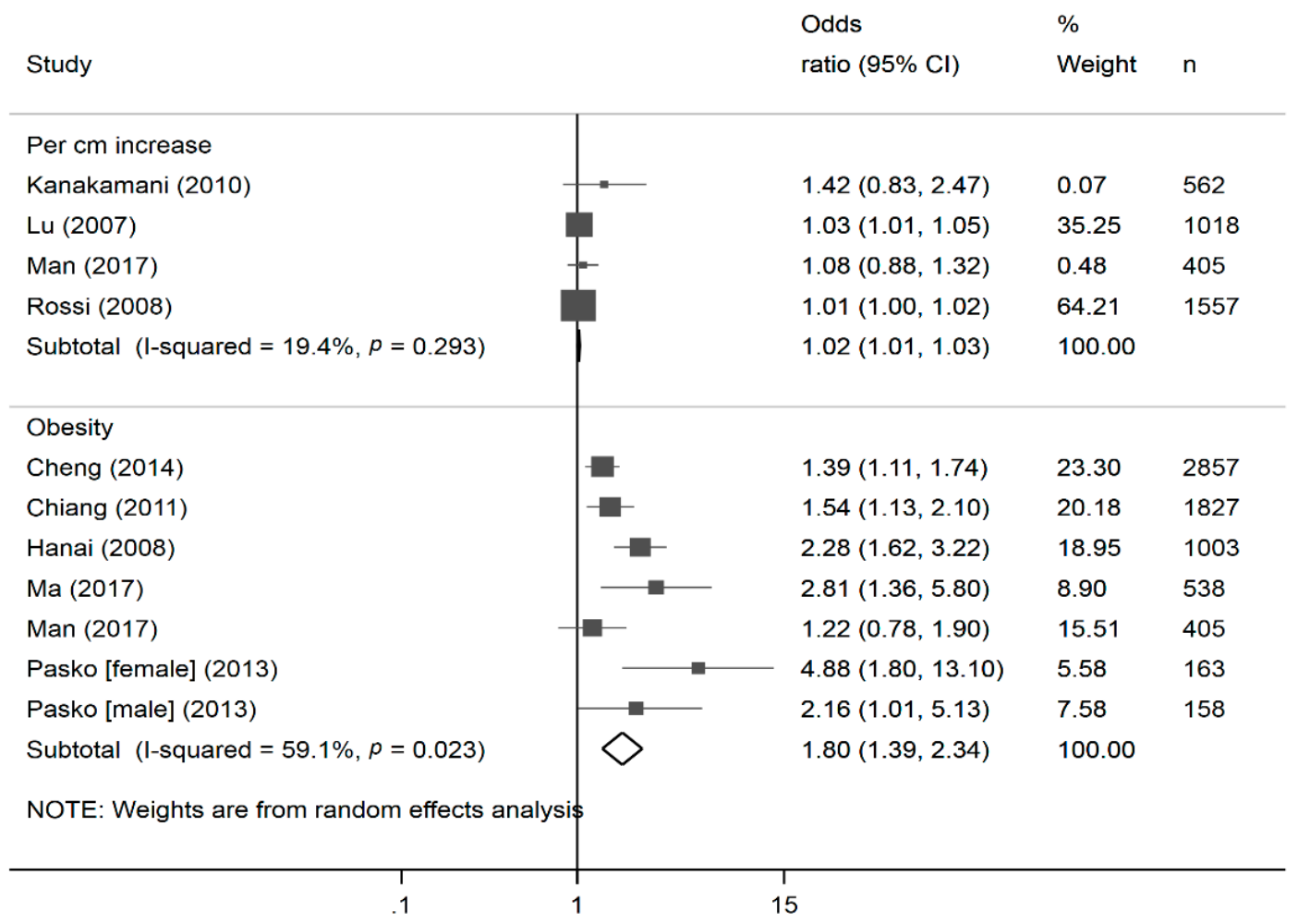

Figure 3. Forest plots * of the association of continuous and categorical waist circumference with diabetic kidney disease. ${ }^{*}$ The size of the box of each study effect corresponds to the relative weight given to that study in the meta-analysis; the diamond refers to the overall pooled estimates with $95 \%$ confidence interval.



Figure 4. Forest plots * of the association of continuous and categorical waist hip/height ratio with diabetic kidney disease. * The size of the box of each study effect corresponds to the relative weight given to that study in the meta-analysis; the diamond refers to the overall pooled estimates with $95 \%$ confidence interval. 


\section{Discussion}

In our clinical study of Asian patients with T2DM, higher BMI was independently associated with greater likelihood of having DKD. WC, WHR and WHtR however, were not independently correlated with DKD presence. While we also found that BMI (i.e., generalised obesity) was associated with greater odds of DKD on our meta-analysis, other parameters of abdominal obesity namely WC, WHR and WHtR, were also associated with a higher likelihood of having DKD. Taken together, our results suggest that both generalized and abdominal obesity may play a role in the pathophysiology of DKD in T2DM, independent of their established roles as major risk factors of hypertension and diabetes, both of which in turn have been demonstrated to be associated with DKD [9]. As such, public health interventions to reduce both forms of obesity in patients with diabetes may also help reduce the likelihood of developing DKD although longitudinal data are needed to support this claim.

Unlike previous research in T2DM patients showing an independent association between abdominal obesity and DKD, as evident in the overall pooled estimates from our meta-analyses, we found no significant relationship between WC, WHR or WHtR and the presence of DKD in our clinical study. Discrepancies between findings could be related to the presence of non-albuminuric DKD, which can make up approximately 50\% of individuals with T2DM and DKD [22]. Analyses stratified by classification of DKD (via eGFR or UACR alone) appear to support this theory: the effect sizes for the association of abdominal obesity markers with DKD appear to be larger for DKD categorized using UACR (Table S3) alone versus DKD categorized using eGFR only (Table S4). As such, larger, longitudinal studies are needed to validate our findings.

We demonstrated that being overweight/obese was associated with increased odds of having DKD in both our sample and meta-analysis of cross-sectional studies, despite the high degree of heterogeneity in the meta-analysis (I-squared value of $76.5 \%$ ). This heterogeneity is likely due to the difference in the classification of obesity and DKD utilized in the various studies; for instance, Belhatem and colleagues defined obesity as BMI of 30 to $<40 \mathrm{~kg} / \mathrm{m}^{2}$, while Low and associates categorized obesity as $>25 \mathrm{~kg} / \mathrm{m}^{2}$. Our cross-sectional results are corroborated by data from large-scale prospective studies [48]. For instance, the Hypertension Detection and Follow-Up Program, a cohort study comprising 5897 patients with hypertension and no kidney disease at baseline, found that the 5 -year incidence of kidney disease was $20 \%$ higher in obese patients compared to those with normal BMI, even after adjustment for presence of T2DM [48]. Unfortunately, we were unable to assess the relationship between BMI and the more severe stages of DKD as we had too few cases of severe DKD. This is important as a few studies have reported that higher BMI is associated with greater rates of survival in those with ESRD [49,50]; a finding that has been attributed to the phenomenon known as the "obesity paradox" [51], where persons with larger body mass are also likely to be healthier (greater muscle mass) with less comorbid conditions. Hence objective measures of body fat (e.g., using dual-energy X-ray absorptiometry or Magnetic Resonance Imaging) [52] in order to enhance our understanding of the nature of the generalized obesity-DKD relationship are warranted.

As our participants were Asian, we also analysed the BMI-DKD relationship using the Asian cut-points defined by WHO in 2003 (Table S5). We found that although the direction of the association remained similar, the significance became attenuated. This attenuation may indicate the existence of a threshold beyond which a higher BMI contributes significantly to the pathogenesis of DKD, and that this threshold may lie closer to the international than Asian classification of generalized obesity. Further longitudinal studies are warranted to verify our findings.

The mechanisms that underlie the relationship between obesity and DKD, independent of $\mathrm{BP}$ and diabetes, are still poorly understood. One hypothesis is that obesity-induced glomerular hyperfiltration, consequent to increased renal tubular sodium reabsorption, results in impairment of renal autoregulation, which then allows for any increase in systemic BP to be transmitted directly to the glomerulus, leading to subsequent renal insult [53]. Excessive lipid deposition into the kidney as a result of obesity can also lead to accumulation of toxic metabolites derived from fatty acid metabolism, 
e.g., diacylglycerols, resulting in mitochondrial dysfunction, endoplasmic reticulum stress, apoptosis, and eventual renal dysfunction [54].

Strengths of this study include a large clinical sample, a comprehensive and standardized clinical assessment protocol, as well as the use of meta-analysis to synthesize available data on the association between the relevant exposures (BMI, WC, WHR and WHtR) and outcome (DKD). Limitations include the cross-sectional nature of this study limiting causal inferences, as well as the low number of subjects with severe DKD, particularly women, making severity analyses non-viable. In addition, our analyses were conducted in a clinical population, which may affect the generalizability of results. Furthermore, UACR and eGFR were assessed using a single spot measurement, which could have led to non-differential misclassification of albuminuria and CKD status, resulting in over or under-reporting of the true prevalence of albuminuria and CKD in these subjects. Additionally, we were unable to verify if the DKD cases in our study were a consequence of diabetes, or of a non-diabetic nature as kidney biopsies were not performed on participants due to the potential risks associated with the procedure. Lastly, we assessed only the relationships between the anthropometric measures of obesity and DKD in our study sample. Future studies should be conducted using objective body fat measures to verify our findings.

\section{Conclusions}

This study and meta-analysis provide evidence that being overweight or obese, as a result of high BMI and/or anthropometric waist measures, was associated with DKD in Asian persons with T2DM. Longitudinal studies with objective assessments of body fat percentage, distribution, location, as well as nature of the renal dysfunction in participants, are warranted to confirm the role of generalized and abdominal obesity in the pathogenesis of DKD. Our results may also inform future clinical trials to determine if objective, rather than anthropometric, markers of obesity are more clinically relevant risk markers of DKD, as well as public health interventions for patients with diabetes to reduce their likelihood of developing DKD.

Supplementary Materials: The following are available online at http:/ / www.mdpi.com/2072-6643/10/11/1685/ s1, Table S1: Multivariable * adjusted association of body mass index, waist circumference, waist-hip-ratio and waist-height-ratio with diabetic kidney diseaset $(N=405)$, Table S2: Summary of included studies in meta-analysis, Table S3: Multivariable adjusted association of body mass index, waist circumference, waist-hip-ratio and waist-height-ratio with diabetic kidney disease * $(N=405)$, Table S4: Multivariable adjusted association of body mass index, waist circumference, waist-hip-ratio and waist-height-ratio with diabetic kidney disease ${ }^{*}(N=405)$, Table S5: Multivariable adjusted association of body mass index with diabetic kidney disease using Asian BMI obesity cut-points * $(N=405)$.

Author Contributions: R.E.K.M.: Conception and design; analysis and interpretation of data; drafting of article. A.T.L.G.: Analysis and interpretation of data; revision of article. E.K.F.: Interpretation of data; revision of article. P.G.: Interpretation of data; revision of article. M.Y.Z.W.: Collection and interpretation of data; revision of article. T.Y.W.: Interpretation of data; revision of article. G.S.W.T.: Interpretation of data; revision of article. B.W.T.: Interpretation of data; revision of article. C.S.: Conception and design; Interpretation of data; revision of article. E.L.L.: Conception and design; interpretation of data; revision of article; final approval of version to be published.

Funding: The Singapore Diabetes Management project was funded by the National Medical Research Council (Singapore) as part of its Centre/Programmatic Project Grant (\#CG/SERI/2010). The grant body had no roles in design, conduct or data analysis of the study, nor in manuscript preparation and approval.

Conflicts of Interest: The authors declare no conflict of interest.

\section{References}

1. Macisaac, R.J.; Ekinci, E.I.; Jerums, G. Markers of and risk factors for the development and progression of diabetic kidney disease. Am. J. Kidney Dis. 2014, 63, S39-S62. [CrossRef] [PubMed]

2. Gheith, O.; Farouk, N.; Nampoory, N.; Halim, M.A.; Al-Otaibi, T. Diabetic kidney disease: World wide difference of prevalence and risk factors. J. Nephropharmacol. 2016, 5, 49-56. [CrossRef] [PubMed] 
3. Collins, A.J.; Foley, R.N.; Gilbertson, D.T.; Chen, S.C. United states renal data system public health surveillance of chronic kidney disease and end-stage renal disease. Kidney Int. Suppl. 2015, 5, 2-7. [CrossRef] [PubMed]

4. Tonelli, M.; Muntner, P.; Lloyd, A.; Manns, B.J.; Klarenbach, S.; Pannu, N.; James, M.T.; Hemmelgarn, B.R.; Alberta Kidney Disease, N. Risk of coronary events in people with chronic kidney disease compared with those with diabetes: A population-level cohort study. Lancet 2012, 380, 807-814. [CrossRef]

5. Barkoudah, E.; Skali, H.; Uno, H.; Solomon, S.D.; Pfeffer, M.A. Mortality rates in trials of subjects with type 2 diabetes. J. Am. Heart Assoc. 2012, 1, 8-15. [CrossRef] [PubMed]

6. Popkin, B.M.; Gordon-Larsen, P. The nutrition transition: Worldwide obesity dynamics and their determinants. Int. J. Obes. Relat. Metab. Disord. 2004, 28, S2-S9. [CrossRef] [PubMed]

7. Vazquez, G.; Duval, S.; Jacobs, D.R., Jr.; Silventoinen, K. Comparison of body mass index, waist circumference, and waist/hip ratio in predicting incident diabetes: A meta-analysis. Epidemiol. Rev. 2007, 29, 115-128. [CrossRef] [PubMed]

8. Nguyen, N.T.; Nguyen, X.M.; Lane, J.; Wang, P. Relationship between obesity and diabetes in a us adult population: Findings from the national health and nutrition examination survey, 1999-2006. Obes. Surg. 2011, 21, 351-355. [CrossRef] [PubMed]

9. Gross, M.L.; Dikow, R.; Ritz, E. Diabetic nephropathy: Recent insights into the pathophysiology and the progression of diabetic nephropathy. Kidney Int. Suppl. 2005, 505, S50-S53. [CrossRef] [PubMed]

10. World Health Organisation. Overweight and Obesity Fact Sheet. Available online: http://www.who.int/ mediacentre/factsheets/fs311/en/. (accessed on 20 February 2018).

11. Ali, A.A.; Al Lami, F.H. Prevalence and determinants of microalbuminurea among type 2 diabetes mellitus patients, baghdad, iraq, 2013. Saudi J. Kidney Dis. Transpl. 2016, 27, 348-355. [CrossRef] [PubMed]

12. Belhatem, N.M.K.; Rouzet, F.; Matallah, N.; Al Baloshi, A.; Travert, F.; Velho, G.; Roussel, R.; Le Guludec, D.; Marre, M.; Hansel, B. Impact of morbid obesity on the kidney function of patients with type 2 diabetes. Diabetes Res. Clin. Pract. 2015, 108, 143-149. [CrossRef] [PubMed]

13. Low, S.K.; Sum, C.F.; Yeoh, L.Y.; Tavintharan, S.; Ng, X.W.; Lee, S.B.; Tang, W.E.; Lim, S.C. Prevalence of chronic kidney disease in adults with type 2 diabetes mellitus. Ann. Acad. Med. Singap. 2015, 44, 164-171. [PubMed]

14. Meguro, S.; Kabeya, Y.; Tanaka, K.; Kawai, T.; Tomita, M.; Katsuki, T.; Oikawa, Y.; Atsumi, Y.; Shimada, A.; Tanaka, M.; et al. Past obesity as well as present body weight status is a risk factor for diabetic nephropathy. Int. J. Endocrinol. 2013, 2013. [CrossRef] [PubMed]

15. Blaslov, K.; Bulum, T.; Duvnjak, L. Waist-to-height ratio is independently associated with chronic kidney disease in overweight type 2 diabetic patients. Endocr. Res. 2015, 40, 194-198. [CrossRef] [PubMed]

16. Hu, J.; Yang, S.; Zhang, A.; Yang, P.; Cao, X.; Li, X.; Goswami, R.; Wang, Y.; Luo, T.; Liao, K.; et al. Abdominal obesity is more closely associated with diabetic kidney disease than general obesity. Diabetes Care 2016, 39, e179-e180. [CrossRef] [PubMed]

17. Tseng, C.H. Waist-to-height ratio is independently and better associated with urinary albumin excretion rate than waist circumference or waist-to-hip ratio in chinese adult type 2 diabetic women but not men. Diabetes Care 2005, 28, 2249-2251. [CrossRef] [PubMed]

18. Jabbar, A.; Irfanullah, A.; Akhter, J.; Mirza, Y.K. Dyslipidemia and its relation with body mass index versus waist hip ratio. J. Pak. Med. Assoc. 1997, 47, 308-310. [PubMed]

19. Brown, C.D.; Higgins, M.; Donato, K.A.; Rohde, F.C.; Garrison, R.; Obarzanek, E.; Ernst, N.D.; Horan, M. Body mass index and the prevalence of hypertension and dyslipidemia. Obes. Res. 2000, 8, 605-619. [CrossRef] [PubMed]

20. Egbe, E.O.; Asuquo, O.A.; Ekwere, E.O.; Olufemi, F.; Ohwovoriole, A.E. Assessment of anthropometric indices among residents of calabar, south-east nigeria. Indian J. Endocrinol. Metab. 2014, 18, 386-393. [PubMed]

21. Man, R.E.; Sabanayagam, C.; Chiang, P.P.; Li, L.J.; Noonan, J.E.; Wang, J.J.; Wong, T.Y.; Cheung, G.C.; Tan, G.S.; Lamoureux, E.L. Differential association of generalized and abdominal obesity with diabetic retinopathy in asian patients with type 2 diabetes. JAMA Ophthalmol. 2016, 134, 251-257. [CrossRef] [PubMed]

22. Retnakaran, R.; Cull, C.A.; Thorne, K.I.; Adler, A.I.; Holman, R.R.; Group, U.S. Risk factors for renal dysfunction in type 2 diabetes: U.K. Prospective diabetes study 74. Diabetes 2006, 55, 1832-1839. [CrossRef] [PubMed] 
23. Laranjinha, I.; Matias, P.; Mateus, S.; Aguiar, F.; Pereira, P.; Perneta Santos, M.; Costa, R.; Lourenco, A.; Guia, J.; Barata, J.D.; et al. Diabetic kidney disease: Is there a non-albuminuric phenotype in type 2 diabetic patients? Nefrologia 2016, 36, 503-509. [CrossRef] [PubMed]

24. Brooke, P.; Bullock, R. Validation of a 6 item cognitive impairment test with a view to primary care usage. Int. J. Geriatr. Psychiatry 1999, 14, 936-940. [CrossRef]

25. World Health Organization. Waist Circumference and Waist-Hip Ratio: Report of a WHO Expert Consultation, Geneva, 8-11 December 2008; World Health Organization: Albany, NY, USA, 2011.

26. Ashwell, M.; Hsieh, S.D. Six reasons why the waist-to-height ratio is a rapid and effective global indicator for health risks of obesity and how its use could simplify the international public health message on obesity. Int. J. Food Sci. Nutr. 2005, 56, 303-307. [CrossRef] [PubMed]

27. Browning, L.M.; Hsieh, S.D.; Ashwell, M. A systematic review of waist-to-height ratio as a screening tool for the prediction of cardiovascular disease and diabetes: 0.5 could be a suitable global boundary value. Nutr. Res. Rev. 2010, 23, 247-269. [CrossRef] [PubMed]

28. Levey, A.S.; Stevens, L.A.; Schmid, C.H.; Zhang, Y.L.; Castro, A.F., 3rd; Feldman, H.I.; Kusek, J.W.; Eggers, P.; Van Lente, F.; Greene, T.; et al. A new equation to estimate glomerular filtration rate. Ann. Intern. Med. 2009, 150, 604-612. [CrossRef] [PubMed]

29. Kdoqi. Kdoqi clinical practice guidelines and clinical practice recommendations for diabetes and chronic kidney disease. Am. J. Kidney Dis. 2007, 49, S12-S154. [CrossRef] [PubMed]

30. Sabanayagam, C.; Wong, T.Y.; Tai, E.S. The ckd-epi equation and mdrd study equation find similar prevalence of chronic kidney disease in asian populations. Ann. Intern. Med. 2009, 151, 892-893. [CrossRef] [PubMed]

31. Teo, B.W.; Xu, H.; Wang, D.; Li, J.; Sinha, A.K.; Shuter, B.; Sethi, S.; Lee, E.J. Gfr estimating equations in a multiethnic asian population. Am. J. Kidney Dis. 2011, 58, 56-63. [CrossRef] [PubMed]

32. Yeo, C.P.; Tan, C.H.; Jacob, E. Haemoglobin a1c: Evaluation of a new hba1c point-of-care analyser bio-rad in2it in comparison with the dca 2000 and central laboratory analysers. Ann. Clin. Biochem. 2009, 46, 373-376. [CrossRef] [PubMed]

33. Wang, Z.; Ding, L.; Huang, X.; Chen, Y.; Sun, W.; Lin, L.; Huang, Y.; Wang, P.; Peng, K.; Lu, J.; et al. Abdominal adiposity contributes to adverse glycemic control and albuminuria in chinese type 2 diabetic patients: A cross-sectional study. J. Diabetes 2017, 9, 285-295. [CrossRef] [PubMed]

34. Borenstein, M.; Hedges, L.V.; Higgins, J.P.; Rothstein, H.R. Introduction to Meta-Analysis; John Wiley \& Sons: Hoboken, NJ, USA, 2011.

35. Hedges, L.V.; Tipton, E.; Johnson, M.C. Robust variance estimation in meta-regression with dependent effect size estimates. Res. Synth. Methods 2010, 1, 39-65. [CrossRef] [PubMed]

36. Tipton, E. Small sample adjustments for robust variance estimation with meta-regression. Psychol. Methods 2015, 20, 375-393. [CrossRef] [PubMed]

37. Jang, C.M.; Hyun, Y.Y.; Lee, K.B.; Kim, H. The association between underweight and the development of albuminuria is different between sexes in relatively healthy korean subjects. Nephrol. Dial. Transplant. 2014, 29, 2106-2113. [CrossRef] [PubMed]

38. Kao, Y.M.; Chen, J.D. Inverse association between body mass index and chronic kidney disease in older diabetic adults. Ann. Epidemiol. 2013, 23, 255-259. [CrossRef] [PubMed]

39. Kanakamani, J.A.; Ammini, A.C.; Gupta, N.; Dwivedi, S.N. Prevalence of microalbuminuria among patients with type 2 diabetes mellitus-A hospital-based study from north india. Diabetes Technol. Ther. 2010, 12, 161-166. [CrossRef] [PubMed]

40. Sakabe, K.; Fukui, M.; Ushigome, E.; Hamaguchi, M.; Senmaru, T.; Yamazaki, M.; Hasegawa, G.; Nakamura, N. Low daily salt intake is correlated with albuminuria in patients with type 2 diabetes. Hypertens. Res. 2012, 35, 1176-1179. [CrossRef] [PubMed]

41. Lu, B.; Wen, J.; Song, X.Y.; Dong, X.H.; Yang, Y.H.; Zhang, Z.Y.; Zhao, N.Q.; Ye, H.Y.; Mou, B.; Chen, F.L.; et al. High prevalence of albuminuria in population-based patients diagnosed with type 2 diabetes in the shanghai downtown. Diabetes Res. Clin. Pract. 2007, 75, 184-192. [CrossRef] [PubMed]

42. Rossi, M.C.; Nicolucci, A.; Pellegrini, F.; Comaschi, M.; Ceriello, A.; Cucinotta, D.; Giorda, C.; Valentini, U.; Vespasiani, G.; De Cosmo, S. Identifying patients with type 2 diabetes at high risk of microalbuminuria: Results of the DEMAND (developing education on microalbuminuria for awareness of renal and cardiovascular risk in diabetes) study. Nephrol. Dial. Transplant. 2008, 23, 1278-1284. [CrossRef] [PubMed] 
43. Cheng, Y.Z.; Zhang, H.; Chen, R.; Yang, F.; Li, W.; Chen, L.; Lin, S.; Liang, G.; Cai, D.; Chen, H. Cardiometabolic risk profiles associated with chronic complications in overweight and obese type 2 diabetes patients in south china. PLOS ONE 2014, 9. [CrossRef] [PubMed]

44. Chiang, S.C.; Lee, J.K.; Chen, C.H.; Chuang, L.M.; Tsan, K.W.; Sheu, W.H.; Wu, D.A.; Wu, T.J.; Lin, K.C.; Juang, J.H.; et al. Justifying the high prevalence of microalbuminuria for type 2 diabetic patients in taiwan with conditional probability approach-A demand ii study. JCMA 2011, 74, 3-10. [CrossRef] [PubMed]

45. Hanai, K.; Babazono, T.; Iwamoto, Y. Renal manifestations of metabolic syndrome in type 2 diabetes. Diabetes Res. Clin. Pract. 2008, 79, 318-324. [CrossRef] [PubMed]

46. Ma, C.M.; Wang, R.; Liu, X.L.; Lu, N.; Lu, Q.; Yin, F.Z. The relationship between hypertriglyceridemic waist phenotype and early diabetic nephropathy in type 2 diabetes. Cardiorenal Med. 2017, 7, 295-300. [CrossRef] [PubMed]

47. Pasko, N.; Toti, F.; Strakosha, A.; Thengjilli, E.; Shehu, A.; Dedej, T.; Ylli, A.; Thereska, N. Prevalence of microalbuminuria and risk factor analysis in type 2 diabetes patients in albania: The need for accurate and early diagnosis of diabetic nephropathy. Hippokratia 2013, 17, 337-341. [PubMed]

48. Kramer, H.; Luke, A.; Bidani, A.; Cao, G.; Cooper, R.; McGee, D. Obesity and prevalent and incident ckd: The hypertension detection and follow-up program. Am. J. Kidney Dis. 2005, 46, 587-594. [CrossRef] [PubMed]

49. Kalantar-Zadeh, K.; Kopple, J.D. Obesity paradox in patients on maintenance dialysis. Contrib. Nephrol. 2006, 151, 57-69. [PubMed]

50. Kalantar-Zadeh, K.; Streja, E.; Kovesdy, C.P.; Oreopoulos, A.; Noori, N.; Jing, J.; Nissenson, A.R.; Krishnan, M.; Kopple, J.D.; Mehrotra, R.; et al. The obesity paradox and mortality associated with surrogates of body size and muscle mass in patients receiving hemodialysis. Mayo Clin. Proc. 2010, 85, 991-1001. [CrossRef] [PubMed]

51. Ades, P.A.; Savage, P.D. The obesity paradox: Perception vs knowledge. Mayo Clin. Proc. 2010, 85, 112-114. [CrossRef] [PubMed]

52. Haarbo, J.; Gotfredsen, A.; Hassager, C.; Christiansen, C. Validation of body composition by dual energy X-ray absorptiometry (dexa). Clin. Physiol. 1991, 11, 331-341. [CrossRef] [PubMed]

53. Maric-Bilkan, C. Obesity and diabetic kidney disease. Med. Clin. N. Am. 2013, 97, 59-74. [CrossRef] [PubMed]

54. Hall, M.E.; do Carmo, J.M.; da Silva, A.A.; Juncos, L.A.; Wang, Z.; Hall, J.E. Obesity, hypertension, and chronic kidney disease. Int. J. Nephrol. Renovasc. Dis. 2014, 7, 75-88. [CrossRef] [PubMed] 